\title{
Determinants of change in airway reactivity over 11 years in the SAPALDIA population
} study

\author{
I. Curjuric*,\#, E. Zemp*\#, J. Dratva**\#, U. Ackermann-Liebrich", P-O. Bridevaux", \\ R.W. Bettschart', M. Brutsche ${ }^{\S}$, M. Frey ${ }^{\dagger}$, M.W. Gerbase ${ }^{\star}$, B. Knöpfli**, N. Künzli*,\#, \\ M. Pons ${ }^{\# \#, ~ J . ~ S c h w a r t z ~}{ }^{\oplus}$, C. Schindler*,\#, T. Rochat ${ }^{\oplus}$ and the SAPALDIA team ${ }^{++}$
}

ABSTRACT: We investigated determinants of change in bronchial reactivity in the Swiss Cohort Study on Air Pollution and Lung Diseases in Adults (SAPALDIA), a population-based cohort with wide age range (29-72 yrs at follow-up).

The role of sex, age, atopic status, smoking and body mass index (BMI) on percentage change in bronchial reactivity slope from the baseline value was analysed in 3,005 participants with methacholine tests in 1991 and 2002, and complete covariate data. Slope was defined as percentage decline in forced expiratory volume in $1 \mathrm{~s}$ from its maximal value per micromole of methacholine.

Bronchial hyperreactivity prevalence fell from 14.3 to $12.5 \%$ during follow-up. Baseline age was nonlinearly associated with change in reactivity slope: participants aged $<\mathbf{5 0}$ yrs experienced a decline and those above an increase during follow-up. Atopy was not associated with change, but accentuated the age pattern ( $p$-value for interaction $=0.038$ ). Smoking significantly increased slope by $21.2 \%$, as did weight gain $(2.7 \%$ increase per BMI unit). Compared with persistent smokers, those who ceased smoking before baseline or during follow-up experienced a significant decrease in slope $(-27.7$ and $-23.9 \%$, respectively). Differing, but not statistically different, age relationships and effect sizes for smoking and BMI between sexes were found.

Mean bronchial reactivity increases after $50 \mathrm{yrs}$ of age, possibly due to airway remodelling or ventilation-perfusion disturbances related to cumulative lifetime exposures.

KEYWORDS: Adult, bronchial hyperreactivity, cohort studies, epidemiologic determinants, methacholine chlorine, population

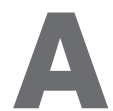
lthough elevated bronchial reactivity plays a major role in asthma [1], the determinants of its change over time have not been extensively researched.

In cross-sectional studies, bronchial reactivity was inversely associated with airway size $[2,3]$ and positively associated with atopy [4, 5]. Smoking has not consistently been shown to increase reactivity [5-8] and a sex difference beyond airway size is debated $[3,8,9]$.

Longitudinal change in bronchial reactivity in the general population has only been investigated by a few cohort studies. In the Normative Aging Study, bronchial reactivity at follow-up was positively correlated with baseline blood basophil counts [10]. New-onset bronchial hyperreactivity (BHR)

was associated with both low and high baseline body mass index (BMI), and linearly with change in BMI [11]. In the European Community Respiratory Health Survey (ECRHS), baseline smokers had higher bronchial reactivity at follow-up [12], and an interaction between allergic sensitisation and sex was found: persistent sensitisation was associated with a reactivity decrease in females but not males [12]. Baseline allergic rhinitis was associated with incident BHR and increased bronchial reactivity at follow-up [13]. Finally, a small study on volunteers from UK general practices showed seasonal patterns, with higher reactivity during summer and winter months [14].

These findings suggest that change in bronchial reactivity might differ between sexes and is

This article has supplementary material available from www.erj.ersjournals.com

Earn CME accreditation by answering questions about this article. You will find these at the back of the printed copy of this issue or online at www.erj.ersjournals.com/site/misc/cmeinfo.xhtml

\section{AFFILIATIONS}

*Swiss Tropical and Public Health Institute,

\#University of Basel, Basel,

"Division of Pulmonary Medicine, University Hospitals of Geneva, Geneva,

+Lungenzentrum, Hirslanden Klinik Aarau,

${ }^{\S}$ Division of Pulmonary Medicine, Cantonal Hospital of St Gallen, St Gallen,

${ }^{f}$ Division of Pulmonary Medicine, Klinik Barmelweid, Barmelweid, ${ }^{\star \star}$ FMH Pädiatrie, Pneumologie und Sportmedizin, Davos, and

\#\#Dipartimento di Medicina,

Ospedale Regionale di Lugano,

Lugano, Switzerland

"Dept of Environmental Health, Harvard School of Public Health, Boston, MA, USA.

${ }^{++} \mathrm{A}$ full list of the members of the SAPALDIA team and their affiliations can be found in the

Acknowledgements section.

\section{CORRESPONDENCE}

I. Curjuric

Swiss Tropical and Public Health

Institute

Socinstrasse 57

PO Box

4002 Basel

Switzerland

E-mail: ivan.curjuric@unibas.ch

Received:

Nov 262009

Accepted after revision:

May 282010

First published online:

June 072010

Online ISSN 1399-3003 
influenced by both allergic conditions and inflammatory processes. Still, knowledge on longitudinal determinants is limited: bronchial reactivity is highly variable in repeated assessments [15], and the cited studies had either short followup $[14,11]$ or restricted age range [13] or sex [11]. There is, thus, a knowledge gap on longitudinal determinants in older populations including males and females. As major pulmonary diseases, such as chronic obstructive pulmonary disease and asthma, increase either in prevalence [16] or severity [17] with age and exhibit important sex differences [18, 19], investigating the timecourse of bronchial reactivity in aged populations is important.

The Swiss Cohort Study on Air Pollution and Lung Diseases in Adults (SAPALDIA) with its population-based sample aged 29-72 yrs at follow-up, detailed health questionnaire data, allergy testing, standardised spirometry and methacholine testing, provides an opportunity to fill this gap.

Thus, we aimed to assess the longitudinal impact of sex, age, atopic status, smoking and BMI on change in bronchial reactivity over the whole age range of the SAPALDIA population.

\section{METHODS AND MATERIALS}

\section{Study design and population}

The SAPALDIA study methodology has been published previously [20]. Briefly, 6,966 randomly selected, 18-60-yr-old adults from eight areas of Switzerland underwent health interview, spirometry and bronchial reactivity testing with methacholine in 1991. At follow-up in 2002, 3,358 underwent the same assessments (fig. 1). 3,005 participants with complete covariate data and no asthma medication were available for multivariable analysis.

All participants gave written consent, and the study was approved by the Swiss Academy of Medical Sciences and local ethics committees.

\section{Assessment procedures}

Health questionnaire

Study participants underwent a health interview on respiratory symptoms, pre-existing pulmonary diseases, smoking behaviour, environmental tobacco smoke (ETS) exposure at home or work, medication use and socioeconomic factors.

Never-smokers had smoked $<20$ packs of cigarettes or $<360 \mathrm{~g}$ of tobacco during their lifetime [21]. Ex-smokers had quit smoking at least 30 days before the interview, and current smokers reported active smoking [21]. We defined six categories of longitudinal smoking behaviour: persistent never-smokers, ex-smokers and smokers for those with unchanged exposure, quitters for baseline smokers becoming ex-smokers at follow-up, uptakers for baseline never-smokers becoming current or ex-smokers at follow-up, and intermittent smokers for the rest.

Asthma was defined as an affirmative answer to both questions "Have you ever had asthma?" and "Was this confirmed by a doctor?". Asthma medication was defined by current intake of inhalers, aerosols or tablets for asthma. Chronic cough was defined as cough during the day or in the morning for $\geqslant 3$ months $\cdot \mathrm{yr}^{-1}$ in the previous $2 \mathrm{yrs}$. Wheezing was present if occurring unrelated to a cold in the 12 months prior to examination.

\section{Spirometry}

Following the ECRHS protocol [22], participants underwent three to eight forced expiratory lung function manoeuvres to achieve a minimum of two measurements complying with American Thoracic Society criteria [23].

\section{Bronchial reactivity testing}

After a starting inhalation of physiological saline solution, methacholine was administered by $\operatorname{MEFAR}_{\mathbb{R}}$ aerosol dosimeters using progressive four-fold solutions of $0.39,1.56,6.25$ and $25 \mathrm{mg} \cdot \mathrm{mL}^{-1}$. Starting from functional residual capacity, participants inhaled to the total lung capacity and held their breath for $4 \mathrm{~s}$. Two forced expiratory manoeuvres were performed 1 and 2 min after inhalation, and the larger forced

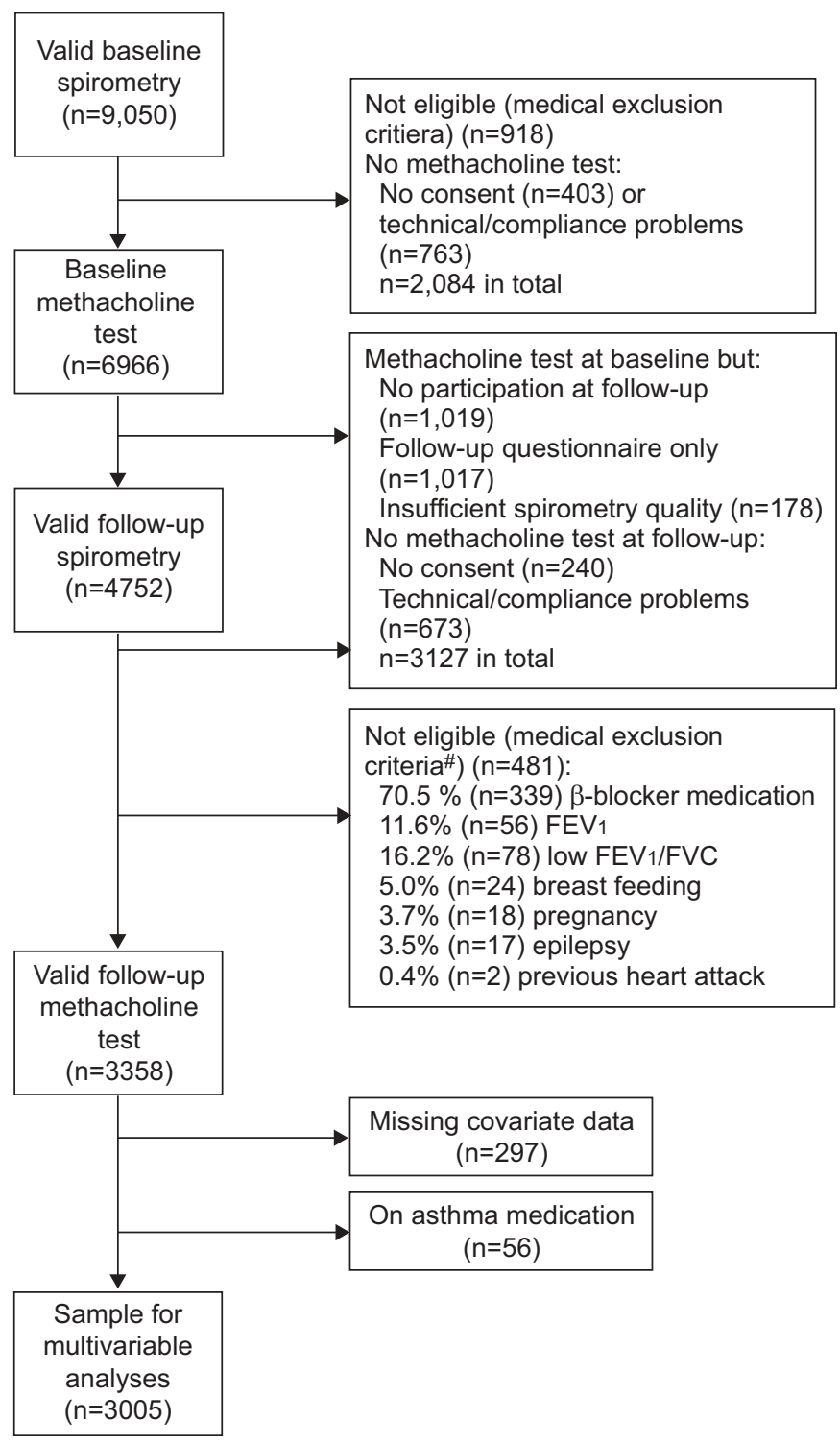

FIGURE 1. Selection of study participants. FEV1: forced expiratory volume in $1 \mathrm{~s}$; FVC: forced vital capacity. \#: numbers do not sum to $100 \%$ as some participants met several criteria. 
expiratory volume in $1 \mathrm{~s}$ (FEV1) measurement was recorded. If FEV1 fell $>10 \%$ from the post-saline level, intermediate, twofold concentrations were applied. No testing was done if FEV1 after saline inhalation fell below $90 \%$ of the maximum spirometry value. The test was stopped if FEV1 fell by $\geqslant 20 \%$ from post-saline measurement, or if a cumulative methacholine dose of $2 \mathrm{mg}$ was reached.

Bronchial reactivity was defined by dose-response slope, similarly to the method employed by O'CONNOR et al. [24]: percentage decline in FEV1 (relative to the maximal test value) divided by the cumulative methacholine dose in micromoles. BHR was defined as FEV1 decline of $\geqslant 20 \%$ from the postsaline measurement up to $2 \mathrm{mg}$ of methacholine.

Test exclusion criteria were myocardial infarction within the last 3 months, severe cardiac failure, $\beta$-blocker medication (including eye drops), epilepsy, pregnancy, lactation, FEV1/forced vital capacity (FVC) ratio $<80 \%$ and $\mathrm{FEV} 1<70 \%$ predicted.

\section{Allergic sensitisation}

In both examinations, atopic sensitisation was assessed by Phadiatop $^{\circledR}$ tests (Phadia, Uppsala, Sweden), radioimmune assays detecting serum immunoglobulin $\mathrm{E}$ antibodies to common inhalatory antigens, such as pollen, household dust mite and animal epithelia [25]. Positive tests had activity levels $\geqslant 0.35 \mathrm{kU} \cdot \mathrm{L}^{-1}$ (for any allergen) and defined atopy.

\section{Statistical analysis}

After adding a small constant (0.01) to each, bronchial reactivity slopes were naturally logarithmised to achieve a more symmetrical distribution [3].The difference between follow-up minus baseline logarithm was used as outcome measure and corresponds to the logarithmised follow-up over baseline slope ratio, as shown below:

$$
\begin{aligned}
& \text { Change in bronchial reactivity slope } \\
& =\ln (\text { slopefollow-up }+0.01)-\ln (\text { slopebaseline }+0.01) \\
& =\ln [(\text { slopefollow-up }+0.01) /(\text { slopebaseline }+0.01)]
\end{aligned}
$$

Exponentiation of regression estimates thus yields geometric means and confidence limits of slope ratios. For clearer interpretation, exponentiated coefficients were expressed as percentage changes from baseline slope (e.g. an exponentiated coefficient of 1.03 as 3\% increase).

To study the effect of selection processes at different stages, characteristics of participants with follow-up methacholine testing, complete covariate data and no asthma medication were compared to those assessed only at baseline, either solely by spirometry $(n=2,084)$ or including methacholine test $(n=3,127)$, using Chi-square, Wilcoxon rank sum and unpaired t-tests.

BHR prevalence and median reactivity slopes at both examinations were described.

Determinants of the logarithmised follow-up over baseline slope ratio were investigated by multivariable mixed linear models including sex, age, allergic sensitisation, BMI, change in BMI, current and ex-smoking, exposure to passive smoke, adjustment for concurrent colds at either examination, sinus and cosinus terms modelling seasonal cyclicity, and random effects for study areas. Continuous covariates, such as age, BMI and pack-years, were also modelled using natural cubic splines specifying five knots positioned as recommended by HARRELL [26]. Pack-yrs smoked in smokers, ex-smokers or both were entered instead of smoking variables. Changes in smoking behaviour were assessed by replacing baseline smoking variables with the categories persistent never-smokers $(n=1,349)$, ex-smokers $(n=606)$, uptakers $(n=99)$, quitters $(n=250)$ and intermittent smokers $(n=100)$ in a model relating to persistent smokers $(n=601)$ as reference. Effects of airway calibre and lung size were not of primary interest, but models were controlled for baseline FEV1, FVC and forced expiratory flow at $25-75 \%$ (FEF25-75\%) (the latter pre-adjusted for sex and FEV1). Participants reporting asthma medication at either examination were expected to influence the observed associations significantly and were thus excluded $(n=56)$.

Robust standard errors were computed to account for heteroscedasticity in residuals. Two-sided significance levels were chosen at $\alpha=0.05$ for main effects and $\alpha=0.1$ for interactions.

Several sensitivity analyses were conducted. In order to assess to what extent effects of study covariates were mediated by lung function and its change, we applied different adjustments to the models, including change in FEV1, FVC and FEF25-75\%, calculated as follow-up minus baseline value, to the baseline variables, replacing lung function variables by \% pred values for FEV1 and FVC [27], and their corresponding change, and leaving out all lung function variables. We checked whether covariate coefficients and p-values were unaltered by the adjustments.

To study the impact of selection processes, we re-ran multivariable analyses, giving more weight to under-represented study participants. Weights consisted of the inverse probability of having methacholine testing at both examinations, as calculated by regressing participation on the same baseline covariates as in the multivariable analyses plus doctordiagnosed asthma and baseline BHR. Finally, regression analyses were re-run after excluding doctor-diagnosed asthma at either examination.

All statistical analyses were performed using STATA version 9.2 (StataCorp, College Station, TX, USA) and SAS Software version 9.1 (SAS Institute Inc., Cary, NC, USA).

\section{RESULTS}

\section{Characteristics of the study populations}

Briefly, $49.1 \%$ of our study participants with complete data on covariates and no asthma medication $(n=3,005)$ were female, $28.3 \%$ were current smokers, $29.4 \%$ atopic, $12.9 \%$ hyperreactive and $3.7 \%$ asthmatic (see online supplementary table O1). Subjects in this sample were significantly less smokingexposed, asthmatic and hyperreactive, had better lung function values, and less wheezing and chronic cough than participants with only baseline spirometry or methacholine test. Main reasons for missing baseline methacholine tests were medical exclusions $(n=918)$ and technical/performance problems $(\mathrm{n}=763)$, while at follow-up, missing data were largely due to complete nonparticipation $(n=1,019)$ or questionnaire assessment only $(n=1,017) .481$ follow-up participants met exclusion criteria for methacholine testing (fig. 1). As would be expected, they fared worse regarding smoking, asthma prevalence, 
hyperreactivity, lung function and respiratory symptoms than our multivariable analysis sample (data not shown).

\section{Prevalence of BHR and bronchial reactivity slope at either examination}

3,358 participants with methacholine testing at both examinations, but not necessarily complete data on covariates, were analysed descriptively (online supplementary table O2). BHR prevalence fell significantly by $-1.8 \%$ from 14.3 to $12.5 \%$ (McNemar $\mathrm{p}=0.0054$ ). Only $46.8 \%$ of the 479 BHR cases at baseline persisted to follow-up. $6.8 \%$ of 2,879 previously normoreactive participants became hyperreactive $(n=195)$.

The median bronchial reactivity slope fell from 1.00 to $0.93 \%$ FEV1 decline $\cdot \mu \mathrm{mol}$ methacholine $\mathrm{e}^{-1}$.

\section{Determinants of change in bronchial reactivity slope}

Analyses were based on 3,005 participants with follow-up methacholine testing, complete covariate data and no asthma medication.

\section{Main effects of determinants}

No significant association between sex and change in reactivity slope presented after controlling for baseline lung function (table 1). When modelled with spline functions, age was nonlinearly associated with the change in reactivity slope: subjects aged $<50$ yrs at baseline experienced a decline over the subsequent 11 yrs of follow-up (fig. 2a). The decline was largest around $30 \mathrm{yrs}$, diminished continuously afterwards and at 50 yrs, a change in direction occurred, with an observable increase thereafter. In participants aged $\geqslant 30 \mathrm{yrs}$, the reactivity slope increased significantly by $1.5 \%$ (95\% CI $0.7-2.3 \%$ ) per year. BMI increase, but not its baseline value, was associated with an increase in reactivity slope of $2.7 \%$ (95\% CI $0.3-5.2 \%)$ per BMI unit. Current baseline smokers experienced a 21.2\% (95\% CI 7.5$36.7)$ increase in reactivity slope compared to never-smokers, corresponding to a $3.6 \%(95 \%$ CI $1.6-5.6 \%)$ increase per 5 packyrs. There were no associations between exposure to ETS or atopy at baseline and change in reactivity slope.

\section{Interactions between determinants}

Sex

Plotting covariate-adjusted age estimates using spline functions suggested different time courses of change in reactivity slope between males and females (fig. $2 b$ and c). Smoking at baseline appeared to increase slope more in females than males (25.0 versus $16.7 \%$, respectively), while for BMI increase, the opposite was observed (5.4\% increase in males versus $0.9 \%$ in females) (table 2). However, none of these sex differences were statistically significant.

\section{Atopy}

Atopic sensitisation showed a significant interaction with age (table 3): the nonlinear age relationship detected in the whole study sample was more pronounced in atopic, but weaker in nonatopic, subjects. When modelling age with polynomial functions, a significant interaction between atopy and the quadratic age term was observed $(p=0.038)$. This model was significantly better than assuming no interaction $(\mathrm{p}=0.027)$.

\section{TABLE 1 Determinants of change in bronchial reactivity slope in participants with complete covariate data and no asthma} medication" $^{\#}$

\begin{tabular}{|c|c|c|}
\hline Covariate & Change in bronchial reactivity slope $\%(95 \% \mathrm{Cl})$ & p-value \\
\hline Female sex & $-3.9(-21.1-16.9)$ & 0.689 \\
\hline \multicolumn{3}{|l|}{ Age } \\
\hline Centered at 40 yrs per yr & $0.9(0.4-1.5)$ & 0.001 \\
\hline Centered at $40 \mathrm{yrs}^{2}$ per $\mathrm{yr}^{2}$ & $0.0(0.0-0.1)$ & 0.024 \\
\hline Centered at 40 yrs only linear term per yr & $1.5(0.7-2.3)$ & $<0.001$ \\
\hline \multicolumn{3}{|l|}{ ETS exposure } \\
\hline Never-smoker & $-1.0(-16.0-16.7)$ & 0.908 \\
\hline Ever-smoker & $10.7(-10.1-36.3)$ & 0.340 \\
\hline Positive Phadiatop test at baseline & $-6.3(-15.8-4.2)$ & 0.230 \\
\hline \multicolumn{3}{|l|}{ BMI } \\
\hline Centered at $25 \mathrm{~kg} \cdot \mathrm{m}^{-2}$ per unit & $-0.1(-1.6-1.4)$ & 0.847 \\
\hline Change between surveys per unit & $2.7(0.3-5.2)$ & 0.030 \\
\hline \multicolumn{3}{|l|}{ Smoking } \\
\hline Being a smoker at baseline & $21.2(7.5-36.7)$ & 0.002 \\
\hline Being an ex-smoker at baseline & $-5.1(-18.2-10.1)$ & 0.487 \\
\hline Pack-yrs in ever-smokers ${ }^{+}$per 5 yrs & $2.1(0.0-4.2)$ & 0.048 \\
\hline Pack-yrs in smokers ${ }^{+}$per 5 yrs & $3.6(1.6-5.6)$ & $<0.001$ \\
\hline Pack-yrs in ex-smokers ${ }^{+}$per 5 yrs & $-2.4(-6.5-1.9)$ & 0.267 \\
\hline
\end{tabular}

Bold indicates statistically significant p-values. ETS: environmental tobacco smoke; BMI: body mass index. ${ }^{*}: \mathrm{n}=3,005$. $:$ from the baseline value; bronchial reactivity slope is defined as percentage change in forced expiratory volume in $1 \mathrm{~s}$ per micromole of methacholine; estimates are expressed in percentage change from baseline slope and adjusted for all other covariates in the table plus concurrent colds at both examinations, seasonal terms, baseline lung function (forced expiratory volume in $1 \mathrm{~s}$, forced vital capacity (FVC) and forced expiratory flow at 25-75\% of FVC) and study area. ${ }^{+}$: pack-yrs in ever-smokers and in smokers/ex-smokers were entered into the model instead of the smoking variables. 

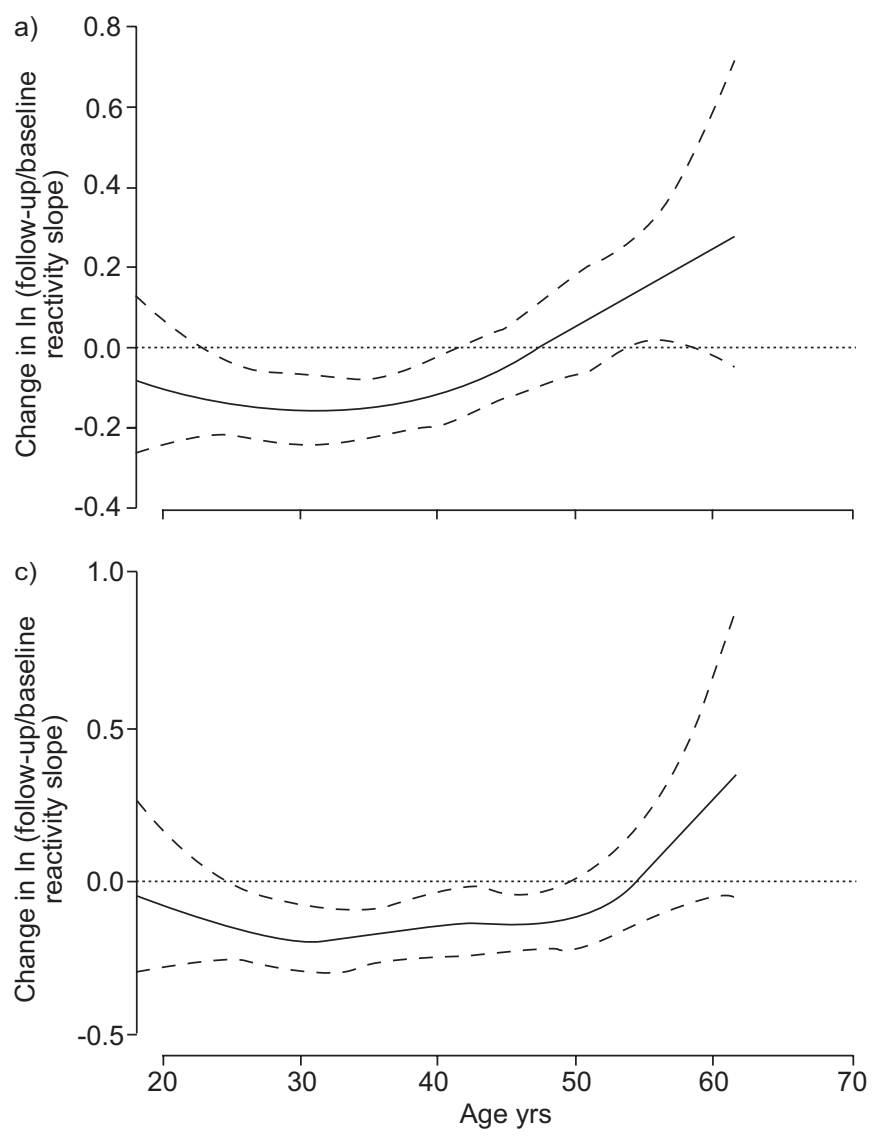

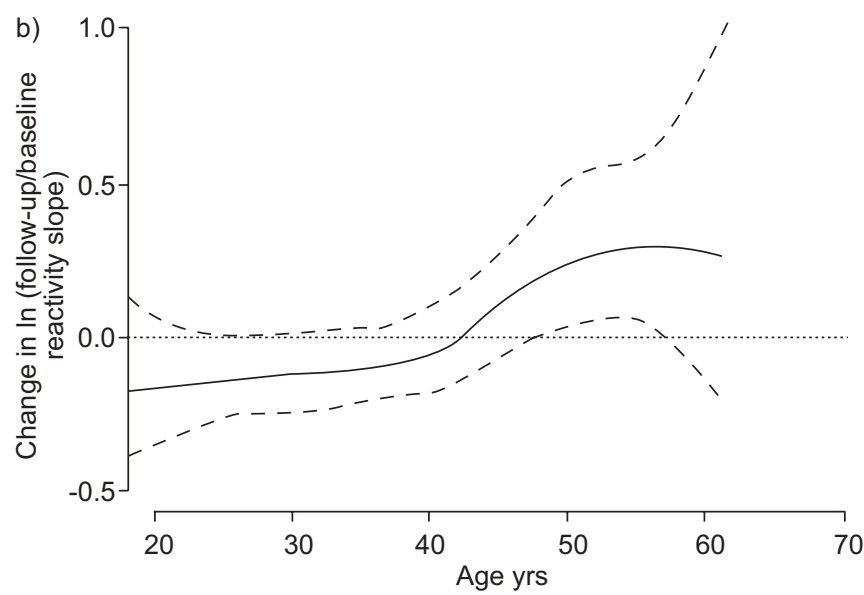

FIGURE 2. Mean change in bronchial reactivity slope over 11 yrs of follow-up according to age at baseline in a) the whole study sample, b) males and c) females. Bronchial reactivity slope is defined as percentage decline in forced expiratory volume in $1 \mathrm{~s}$ per micromole of methacholine. —-: mean; -----: $95 \% \mathrm{Cl}$

\section{TABLE 2 Determinants of change in bronchial reactivity slope in males and females separately}

Covariate

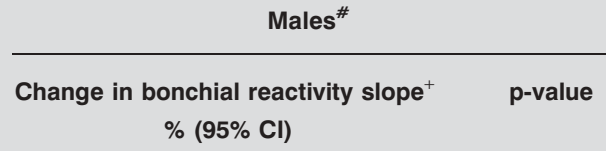
$\%(95 \% \mathrm{Cl})$
Females

Change in bonchial reactivity slope $^{+} \%(95 \% \mathrm{Cl})$

\begin{tabular}{|c|c|c|c|c|}
\hline \multicolumn{5}{|l|}{ Age } \\
\hline Centered at 40 yrs per yr & $1.4(0.5-2.3)$ & 0.003 & $0.6(-0.1-1.3)$ & 0.094 \\
\hline \multicolumn{5}{|l|}{ ETS exposure } \\
\hline Ever-smoker & $11.5(-17.7-51.0)$ & 0.483 & $8.5(-16.7-41.4)$ & 0.545 \\
\hline Positive Phadiatop test at baseline & $-9.9(-23.3-5.9)$ & 0.207 & $-3.2(-15.4-10.6)$ & 0.629 \\
\hline \multicolumn{5}{|l|}{ BMI } \\
\hline \multicolumn{5}{|l|}{ Smoking } \\
\hline Being a smoker at baseline & $16.7(-2.9-40.2)$ & 0.100 & $25.0(6.6-46.6)$ & 0.006 \\
\hline Being an ex-smoker at baseline & $-8.6(-28.1-16.2)$ & 0.461 & $-4.0(-19.2-14.0)$ & 0.641 \\
\hline
\end{tabular}




\section{TABLE 3 Determinants of change in bronchial reactivity slope according to Phadiatop test result at baseline}

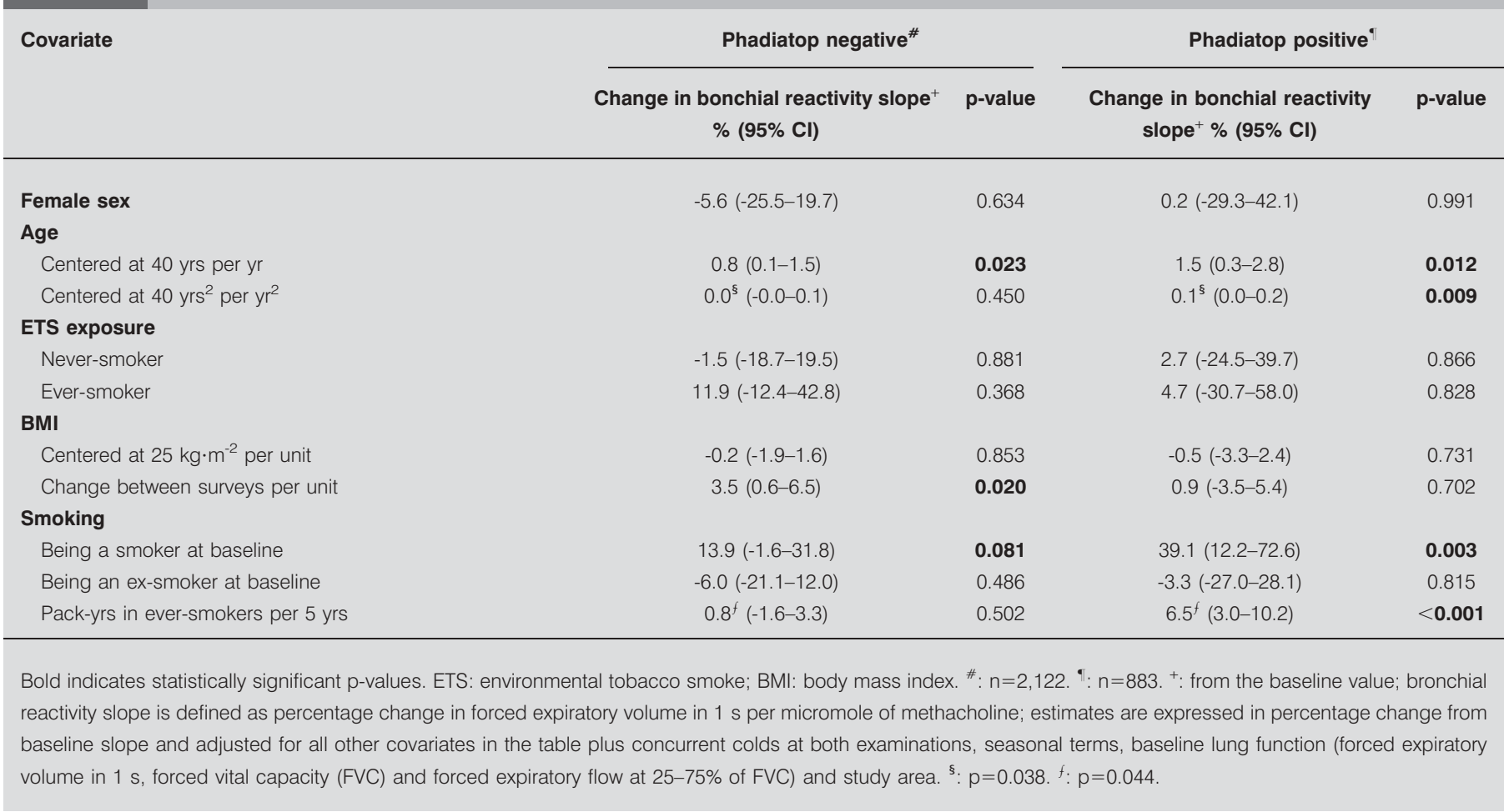

Smoking at baseline was associated with a large and significant increase of $39.1 \%$ (95\% CI $12.2-72.6 \%$ ) in atopic persons only. However, the interaction with atopy became significant only when analysing pack-yrs ( $\mathrm{p}$-value for interaction (pinteraction) $=0.044$ ).

\section{Smoking}

The nonlinear relationship between age and change in reactivity slope was most pronounced in nonsmokers (fig. 3), and appeared different in ever-smokers (pinteraction $=0.073$ ). In

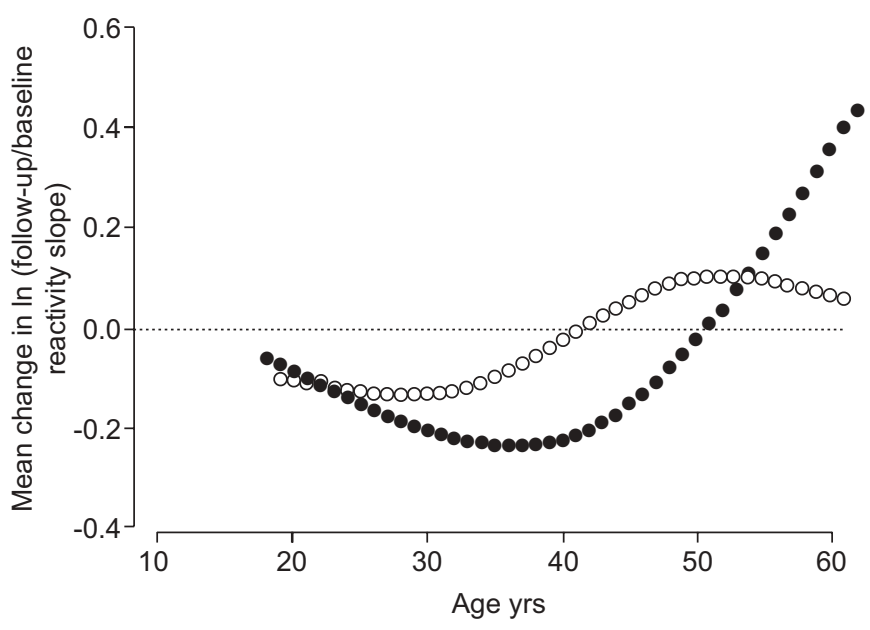

FIGURE 3. Mean change in bronchial reactivity slope over 11 yrs of follow-up according to baseline smoking status. Bronchial reactivity slope is defined as the percentage decline in forced expiratory volume in $1 \mathrm{~s}$ per micromole of methacholine. $\bigcirc$ : ever-smokers; $\bullet$ : never-smokers. current and ex-smokers, the turning point to increasing slope occurred earlier, around age 40 yrs, and no linear increase in slope was observed thereafter. Effect estimates for the other covariates remained unaffected by smoking status.

Compared with persistent smokers, participants quitting smoking before the first examination or during follow-up experienced a $27.7 \%(95 \%$ CI $15.9-37.9 \%)$ and $23.9 \%(95 \% \mathrm{CI}$ $6.8-37.8 \%$ ) decline in bronchial reactivity slope respectively (table 4), which was comparable to persistent never-smokers (-24.6\% decline, 95\% CI 14.5-33.5\%).

$\mathrm{BMl}$

No significant interactions were found for BMI at baseline or its change.

\section{Sensitivity analyses}

Effect estimates and strengths of associations for age, smoking, change in BMI and atopy were unaffected by the method of adjustment for change in lung function (online supplementary table O3). However, when using \% pred values and corresponding change for FEV1 and FVC, female sex was significantly associated with a decrease in reactivity slope by $13.8 \%$ (95\% CI $4.2-22.4 \%)$. As the only lung function variable significantly associated with change in reactivity slope, decline in FEV1 \% pred increased slope by $1.2 \%$ (95\% CI 0.3-2.1) for each percent decline.

Repeating regression analyses with weights for each observation inverse to the probability of participation yielded the same results.

Exclusion of participants with doctor-diagnosed asthma resulted in similar smoking effect estimates for males and females, but no significant alterations of other estimates (data not shown). 
TABLE 4 Effects of change in smoking behaviour during 11 yrs of follow-up on change in bronchial reactivity slope

\begin{tabular}{lccc}
$\begin{array}{l}\text { Category of change in smoking } \\
\text { behaviour }\end{array}$ & Subjects $\mathbf{n}$ & Change in bonchial reactivity slope ${ }^{\#} \mathbf{\%}(\mathbf{9 5 \%} \mathbf{C l}) \quad$ Ref. \\
\hline Persistent smokers & 601 & $-27.7(-37.9--15.9)$ & $<0.001$ \\
Persistent ex-smokers & 606 & $-23.9(-37.8--6.8)$ & $-17.3(-37.6-9.4)$ \\
Quitters & 250 & $-12.8(-30.0-8.8)$ & 0.008 \\
Uptakers & 99 & $-24.6(-33.5--14.5)$ & 0.202 \\
Intermittent smokers & 100 & & 0.156 \\
Persistent never-smokers & 1349 & & $<0.001$ \\
\hline
\end{tabular}

Ref.: reference category. \#: percentage change in bronchial reactivity slope from the baseline value; bronchial reactivity slope is defined as percentage change in forced expiratory volume in $1 \mathrm{~s}$ (FEV1) per micromole of methacholine; estimates are from a mixed linear regression model with random effects for area and adjusting for sex, age, age squared, body mass index (BMI), change in BMI, atopy, FEV1, forced expiratory volume at $25-75 \%$ of forced vital capactiy (FVC), FVC, occurrence of colds and seasonal terms.

\section{DISCUSSION}

In our general population sample of 29-72-yr-old adults, we found a $1.8 \%$ decrease in BHR prevalence and a $7 \%$ decrease in median reactivity slope over the course of 11 yrs. We observed a significant negative association of female sex with change in reactivity slope only after controlling for lung function using $\%$ pred values. These reflect the sex-specific deviation in lung function from an age- and height-dependent expected value, and preclude the assumption of equal effects of a given absolute lung volume or change in both sexes. But they do not take account of smaller absolute airway sizes in females, which might importantly influence the concentration of the stimulus at the airway walls. In accordance with other studies [12], we have found no sex effect once baseline lung function values were controlled for. The observed sex-specific age relationships of reactivity suggest different age-courses of bronchial reactivity between sexes, maybe due to a higher level of reactivity as a consequence of smaller airway size in females. Additionally, the apparent stronger smoking effect suggests higher susceptibility to environmental exposures in females.

Our findings relating to the nonlinear association of change in bronchial reactivity slope with age are new and not described by previous longitudinal studies. These mostly focused on other determinants [11-13] and differed regarding age distribution. An age-associated increase in bronchial reactivity has been described in cross-sectional studies [28]. At the time of our own cross-sectional analysis [3], participants were $11 \mathrm{yrs}$ younger and the switch occurring in older age was not detectable. Based on the limited literature on bronchial reactivity in older populations, we can only speculate about possible mechanisms. Airway remodelling or ventilationperfusion disturbances, which increase bronchial reactivity $[29,30]$, might be induced by cumulative, lifetime exposures to different noxious substances. Furthermore, loss of tissue elasticity in the ageing lung might cause a tendency for airway closure and air trapping with increased residual volume. It is likely that these mechanisms are not adequately captured in our models, even those including change in lung function.

In accordance with other studies [10,12], we did not observe a direct effect of atopy on change in reactivity slope. But atopy accentuated the relationship with age and enhanced smoking effects. We found a strong, positive relationship between smoking and change in reactivity slope, a finding inconsistently described [10, 12], possibly due to shorter follow-up times. Profitting from the large sample size of our study, we could also show that quitting smoking has a profound beneficial effect on change in reactivity. Power to assess effects of taking up smoking was, however, limited.

Finally, we observed that change in BMI, but not its baseline value, was positively associated with change in reactivity slope. These effects could be mediated by increased levels of subclinical inflammation from adipose tissue. Our study benefitted from a relatively large sample size, wide age distribution for both sexes, standardised spirometry and methacholine testing, and detailed health interviews. However, it also had limitations: the substantial loss to follow-up over 11 years caused by nonparticipation or only partial participation, technical problems, health-related exclusions or refusal, and associated with smoking, lower lung function values and higher bronchial reactivity slope, leads us to expect bias. Our sensitivity analyses giving more weight to underrepresented groups within the study sample yielded the same results, though. Effect estimates for age, smoking, BMI increase and atopy also remained stable after exclusion of known asthmatics or adjustment for lung function in different ways. Loss to follow-up is, thus, unlikely to invalidate our findings, but due to the stringent selection processes, their generalisability is limited to relatively healthy participants with no or only mild-tomoderate asthmatic disease, or mild lung function impairment. Thus, our results mostly represent the natural course of bronchial reactivity in a general population sample of healthy adults.

In conclusion, in its natural course, bronchial reactivity slope tends to increase in middle- to old-aged persons after showing a favourable attenuation during young adulthood, a pattern more pronounced in atopic individuals, but less evident in smokers. Airway remodelling, ventilation-perfusion disturbances and airway closure associated with the ageing lung possibly underlie the increase in older age. Females might present a different agecourse in airway reactivity due to their smaller lung and airway size or greater susceptibility to environmental exposures.

\section{SUPPORT STATEMENT}

This work was supported by the Swiss National Science Foundation (grant numbers 33CSCO-108796, 3247BO-104283, 3247BO-104288, 
3247BO-104284，3247-065896, 3100-059302, 3200-052720, 3200-042532 and 4026-028099), the Federal Office for Forest, Environment and Landscape, the Federal Office of Public Health, the Federal Office of Roads and Transport, the canton governments of Aargau, Basel-Stadt, Basel-Land, Geneva, Luzern, Ticino and Zurich, the Swiss Lung League, the canton's Lung League of Basel Stadt/Basel Landschaft, Geneva, Ticino and Zurich.

\section{STATEMENT OF INTEREST}

None declared.

\section{ACKNOWLEDGEMENTS}

The members of the Swiss Cohort Study on Air Pollution and Lung Diseases in Adults (SAPALDIA) team are as follows. Study directorate: T. Rochat (pneumology; University Hospital, Geneva, Switzerland), U. Ackermann-Liebrich (epidemiology; University of Basel, Basel, Switzerland), J.M. Gaspoz (cardiology; University Hospital, Geneva, Switzerland), N Künzli (epidemiology/exposure; SwissTPH, Basel, Switzerland), L.J.S. Liu (exposure; SwissTPH), N.M. Probst Hensch (epidemiology/genetic and molecular biology; SwissTPH) and C. Schindler (statistics; SwissTPH). Scientific team: J.C. Barthélémy (cardiology; University Hospital, St. Etienne, France), W. Berger (genetic and molecular biology; University of Zürich, Zürich, Switzerland), R. Bettschart (pneumology; Hirslanden Klinik, Aarau, Switzerland), A. Bircher (allergology; University Hospital, Basel, Switzerland), G. Bolognini (pneumology; Regional Hospital, Mendrisio, Switzerland), O. Brändli (pneumology; Höhenklinik, Wald, Switzerland), M. Brutsche (pneumology; Cantonal Hospital, St Gallen, Switzerland), L. Burdet (pneumology; Regional Hospital, Payerne, Switzerland), M. Frey (pneumology; Klinik Barmelweid, Aarau), M.W. Gerbase (pneumology; University Hospital, Geneva, Switzerland), D. Gold (epidemiology/cardiology/pneumology; Harvard School of Public Health, Boston, MA, USA), W. Karrer (pneumology; Luzerner Höhenklinik, Crans Montana, Switzerland), R. Keller (pneumology; Aarau, Switzerland), B. Knöpfli (pneumology; Davos, Switzerland), U Neu (exposure; ProClim, Bern, Switzerland), L. Nicod (pneumology; University Hospital, Lausanne, Switzerland), M. Pons (pneumology; Regional Hospital, Lugano, Switzerland), E. Russi (pneumology; University Hospital, Zürich), P. Schmid-Grendelmeyer (allergology; University Hospital, Zürich), J. Schwartz (epidemiology; Harvard School of Public Health), P. Straehl (exposure; BAFU, Bern, Switzerland), J.M. Tschopp (pneumology; Centre Valaisan de Pneumologie, Crans Montana), A. von Eckardstein (clinical chemistry; University Hospital, Zürich), J.P. Zellweger (pneumology; CHUV, Lausanne) and E. Zemp Stutz (epidemiology; SwissTPH). Scientific team at coordinating centers: P.O. Bridevaux (pneumology; University Hospital, Geneva), I. Curjuric (epidemiology; SwissTPH), J. Dratva (epidemiology; SwissTPH), D. Felber Dietrich (cardiology; SwissTPH), D. Keidel (statistics; SwissTPH), M. Imboden (genetic and molecular biology; SwissTPH), H. Phuleria (exposure; SwissTPH), E. Schaffner (statistics; SwissTPH), G.A. Thun (genetic and molecular biology; SwissTPH), A. Ineichen (exposure; SwissTPH) and M. Ritter (exposure; University of Basel).

The study could not have been done without the help of the study participants, technical and administrative support and the medical teams and field workers at the local study sites.

Local fieldworkers: M. Broglie, M. Bünter and D. Gashi (Aarau); R. Armbruster, T. Damm, U. Egermann, M. Gut, L. Maier, A. Vögelin and L. Walter (Basel); D. Jud and N. Lutz (Davos); M. Ares, M. Bennour, B. Galobardes and E. Namer (Geneva); B. Baumberger, S. Boccia Soldati, E. Gehrig-Van Essen, S. Ronchetto (Lugano); C. Bonvin and C. Burrus (Montana); S. Blanc, A.V. Ebinger, M.L. Fragnière and J. Jordan (Payerne); R. Gimmi, N. Kourkoulos and U. Schafroth (Wald).

Administrative staff: N. Bauer (SwissTPH), D. Baehler, C. Gabriel (both University Hospital, Geneva, Switzerland), R. Nilly and F Meier (both SwissTPH).

\section{REFERENCES}

1 Covar RA. Bronchoprovocation testing in asthma. Immunol Allergy Clin North Am 2007; 27: 633-649.

2 Paoletti P, Carrozzi L, Viegi G, et al. Distribution of bronchial responsiveness in a general population: effect of sex, age, smoking, and level of pulmonary function. Am J Respir Crit Care Med 1995; 151: 1770-1777.

3 Schwartz J, Schindler C, Zemp E, et al. Predictors of methacholine responsiveness in a general population. Chest 2002; 122: 812-820.

4 Chinn S, Burney P, Sunyer J, et al. Sensitization to individual allergens and bronchial responsiveness in the ECRHS. European Community Respiratory Health Survey. Eur Respir J 1999; 14: 876-884.

5 Burney PG, Britton JR, Chinn S, et al. Descriptive epidemiology of bronchial reactivity in an adult population: results from a community study. Thorax 1987; 42: 38-44.

6 Sunyer J, Anto JM, Kogevinas M, et al. Smoking and bronchial responsiveness in nonatopic and atopic young adults. Spanish Group of the European Study of Asthma. Thorax 1997; 52: 235-238.

7 Rijcken B, Schouten JP, Mensinga TT, et al. Factors associated with bronchial responsiveness to histamine in a population sample of adults. Am Rev Respir Dis 1993; 147: 1447-1453.

8 Britton J, Pavord I, Richards K, et al. Factors influencing the occurrence of airway hyperreactivity in the general population: the importance of atopy and airway calibre. Eur Respir J 1994; 7: 881-887.

9 Leynaert B, Bousquet J, Henry C, et al. Is bronchial hyperresponsiveness more frequent in women than in men? A populationbased study. Am J Respir Crit Care Med 1997; 156: 1413-1420.

10 Sparrow D, O'Connor GT, Rosner B, et al. Predictors of longitudinal change in methacholine airway responsiveness among middle-aged and older men: the Normative Aging Study. Am J Respir Crit Care Med 1994; 149: 376-381.

11 Litonjua AA, Sparrow D, Celedon JC, et al. Association of body mass index with the development of methacholine airway hyperresponsiveness in men: the Normative Aging Study. Thorax 2002; 57: 581-585.

12 Chinn S, Jarvis D, Luczynska CM, et al. An increase in bronchial responsiveness is associated with continuing or restarting smoking. Am J Respir Crit Care Med 2005; 172: 956-961.

13 Shaaban R, Zureik M, Soussan D, et al. Allergic rhinitis and onset of bronchial hyperresponsiveness: a population-based study. Am J Respir Crit Care Med 2007; 176: 659-666.

14 Trigg CJ, Bennett JB, Tooley M, et al. A general practice based survey of bronchial hyperresponsiveness and its relation to symptoms, sex, age, atopy, and smoking. Thorax 1990; 45: 866-872.

15 Beckett WS, Pace PA, Sferlazza SJ, et al. Annual variability in methacholine responsiveness in nonasthmatic working adults. Eur Respir J 1997; 10: 2515-2521.

16 Halbert RJ, Natoli JL, Gano A, et al. Global burden of COPD systematic review and meta-analysis. Eur Respir J 2006; 28: 523-532.

17 Stupka E, deShazo R. Asthma in seniors: part 1. Evidence for underdiagnosis, undertreatment, and increasing morbidity and mortality. Am J Med 2009; 122: 6-11.

18 Postma DS. Gender differences in asthma development and progression. Gend Med 2007; 4: Suppl. B, S133-S146.

19 Han MK, Postma D, Mannino DM, et al. Gender and chronic obstructive pulmonary disease: why it matters. Am J Respir Crit Care Med 2007; 176: 1179-1184.

20 Ackermann-Liebrich U, Kuna-Dibbert B, Probst-Hensch NM, et al. Follow-up of the Swiss Cohort Study on Air Pollution and Lung Diseases in Adults (SAPALDIA 2) 1991-2003: methods and characterization of participants. Soz Praventivmed 2005; 50: 245-263.

21 Epidemiology Standardization Project, American Thoracic Society. Recommended respiratory disease questionnaires for use with adults and children in epidemiological research. Am Rev Respir Dis 1978; 118: 7-52. 
22 Burney PG, Luczynska C, Chinn S, et al. The European Community Respiratory Health Survey. Eur Respir J 1994; 7: 954-960.

23 Standardization of spirometry, 1994 Update. American Thoracic Society. Am J Respir Crit Care Med 1995; 152: 1107-1136.

24 O'Connor G, Sparrow D, Taylor D, et al. Analysis of dose-response curves to methacholine. An approach suitable for population studies. Am Rev Respir Dis 1987; 136: 1412-1417.

25 Eriksson NE. Allergy screening with Phadiatop and CAP Phadiatop in combination with a questionnaire in adults with asthma and rhinitis. Allergy 1990; 45: 285-292.

26 Harrell FE. Regression modelling strategies with applications to linear models, logistic regression, and survival analysis. New York, Springer, 2001.
27 Quanjer PH, Tammeling GJ, Cotes JE, et al. Lung volumes and forced ventilatory flows. Report Working Party Standardization of Lung Function Tests, European Community for Steel and Coal. Official Statement of the European Respiratory Society. Eur Respir J Suppl 1993; 16: 5-40.

28 Scichilone N, Messina M, Battaglia S, et al. Airway hyperresponsiveness in the elderly: prevalence and clinical implications. Eur Respir J 2005; 25: 364-375.

29 Berend N, Salome CM, King GG. Mechanisms of airway hyperresponsiveness in asthma. Respirology 2008; 13: 624-631.

30 Laprise C, Laviolette M, Boutet M, et al. Asymptomatic airway hyperresponsiveness: relationships with airway inflammation and remodelling. Eur Respir J 1999; 14: 63-73. 